\title{
Sprachformen als Quellen zur Kulturgeschichte zwischen Saale und Elbe
}

\author{
von \\ KARLHEINZ HENGST
}

Die folgenden Ausführungen bieten Antworten zu zwei Fragenkomplexen, die sich in der aktuellen interdisziplinären Diskussion um die neuen Einsichten zum Namen Jena ${ }^{1}$ und aus sich daran anschließenden Betrachtungen bis hin zu den Jabna-Namen ${ }^{2}$ ergeben haben. Deutlich wird dabei die kulturgeschichtliche Aussagekraft der sprachlichen Formen im Kontext von besiedlungsgeschichtlichen Fakten und geografischgeologischen Gegebenheiten.

\section{Die Jena-Namen in nun erweiterter Sicht}

\section{Warum und wozu Antworten?}

Aus ingenieurwissenschaftlicher Sicht ist $\mathrm{zu}$ einem sprachwissenschaftlichen Befund eine ausführliche Stellungnahme erschienen. Als Vertreter einer Nachbarwissenschaft hat Hans Schmigalla zu einem Beitrag, der die Jena-Namen zum Gegenstand hatte und 2015 erschienen war, ${ }^{3}$ im Jahrgang 2016 ausführlich Stellung bezogen. ${ }^{4}$ Damit ist aus folgenden Gründen Anlass gegeben, den Dialog fortzusetzen: Erstens hat Hans Schmigalla eine sehr sorgfältig und fundiert gestaltete Studie zu den Jena-Namen an Saale und Unstrut aus geografischer, ingenieurgeologischer und logistischer Fachperspektive geliefert. Gewässer haben ja bekanntlich in der Kulturgeschichte aller Ethnien stets eine besondere Rolle gespielt. Zweitens hat er dabei aus einem Blickwinkel, der dem Sprachforscher und wohl auch dem Historiker nie zugänglich geworden wäre, die außersprachlichen Verhältnisse als die letztlich immer entscheidende Grundlage für die zur sprachlichen Äußerung mittels Namenbildung führenden Motive genauestens untersucht und seine gewonnenen Erkenntnisse klar dargelegt. Drittens hat er mit seinen vertiefenden Untersuchungen eine Bestätigung für die ursprünglich rein sprachhistorisch erwiesenen Fakten und Schlussfolgerungen geboten, diese mit geografischen und geologischen Beweisen sowie mit Resultaten aus der Altwegeforschung untermauert, was wiederum einen kulturgeschichtlichen Aspekt besitzt. Viertens hat er seinerseits einige Fragen an die Sprachforschung mit Relevanz auch für die mittelalterliche Kulturgeschichte gestellt. Auf diese Fragen gilt es nun, klare und begründete Antworten zu geben.

1 Karlheinz Hengst, Die Jena-Namen und ihr kulturgeschichtlicher Inhalt im Zusammenhang mit neuen historischen Forschungen, in: Zeitschrift für Thüringische Geschichte 69 (2015), S. 7-32.

2 Hans Schmigalla, Über Felsbänke und markierte Furten - Annotationen zu den Jena-Namen, in: Zeitschrift für Thüringische Geschichte 70 (2016), S. 175-196.

3 Wie Anm. 1.

4 Wie Anm. 2. 


\section{Welche Fragen sind zu beantworten?}

Ausgeklammert bleiben zunächst die im umfangreichen Aufsatz von Hans Schmigalla mit erwähnten und teilweise neben den Jena-Namen ausführlich einbezogenen Namen für Örtlichkeiten, also Rudigene, Rothejane/Rothe Jahna sowie die Gewässernamen Jahna und Jabnabach. ${ }^{5}$ Diese Onyme und ihre Überlieferung verdienen eine differenzierte Behandlung im nachfolgenden Abschnitt II.

Zur Sicherung einer leichten Vergleichbarkeit werden nun nachfolgend die einzelnen aufgeworfenen Fragen nacheinander und mit jeweiliger Seitenangabe aus der Publikation von Schmigalla, hier bezeichnet als „geografisch-geologisch-logistische Studie" (dafür kurz GGLS), vom Jahr 2016 genannt:

1. „Es handelt sich um die Klärung der realienkundlichen Frage, ob es gerechtfertigt ist, davon auszugehen, dass jeder Durchgang durch ein Gewässer oder nur ein solcher mit ganz speziellen Eigenschaften mit dem in Iani enthaltenen ian-bezeichnet werden konnte.“ (S. 175). Diese Frage führt zu einer vertiefenden Betrachtung der Jena-Namen. Vergleichbar mit einem onomasiologischen Ansatz lässt sich die neue Aufgabe auch so formulieren: Was konkret wurde warum mit ian/Iani bezeichnet bzw. benannt? Warum treten die Jena-Namen nur an zwei Flüssen auf? Was kann die Ursache dafür sein?

Da Benennungen durch Menschen für Erscheinungen in ihrer Umgebung erfolgen, ist die Frage nach den in der Realität zu suchenden Ursachen für jede sprachliche Bezeichnung sowie jeden Namen nicht nur legitim, sondern erforderlich. Damit wird angestrebt, die zunächst allein aus der sprachwissenschaftlichen Untersuchung gebotene Bedeutungsangabe zu ian als ,begehbarer/befahrbarer Durchgang، für eine Furt in einem Fließgewässer weiter zu präzisieren. Oder anders formuliert, verbindet sich damit zugleich die Frage: Worin unterscheidet sich möglicherweise die Bedeutung oder der Bedeutungsumfang des früh angewandten Lexems ian von gut bekanntem althochdeutsch furt, altsächsisch. vord ,Furt'?

Die einzelnen Befunde in der GGLS aus den Untersuchungen an den Flüssen in Verbindung mit dem Vorkommen der Jena-Namen haben dazu eine neue Erkenntnis ermöglicht: Das den heutigen Ortsnamen zugrunde liegende Wort fand dánn Anwendung für einen ,Durchgang', wenn im Fließgewässer auf dessen Soble naturbedingt so etwas wie ein aufscheinender Gang erkennbar war. Felsbänke ${ }^{6}$ auf dem Gewässergrund haben offensichtlich den Eindruck einer den Fluss querenden Schneise oder eines Korridors erwecken können. Damit schließt sich diese Beobachtung an den bei mittelhochdeutsch $j \bar{a} n$,Reihe gemähten Grases, geschnittenen Getreides' vorhandenen Bedeutungsinhalt an, der auch dieses Sem z. B. in der Landwirtschaft mit einer, breiten Bahn' des Schnitters bzw. einer Schneise/eines Korridors im Weinanbau bei ,Gang zwischen den Rebstöcken' verbindet. Aus sprachwissenschaftlicher Sicht ist folglich vollauf zu begrüßen, dass ausdrücklich der Frage nachgegangen worden ist, ob „begehbarer/befahrbarer Durchgang“ ausreichend die Bedeutung von mittelalterlich ian erfasst.

5 Vgl. Schmigalla, Felsbänke (wie Anm. 2), S. 190-196.

6 Hierzu eine kurze Erläuterung, die mir wichtig erscheint für das Verständnis und die ich auch erst aus dem Dialog mit dem Fachmann gewonnen habe: Es muss sich also um fest mit dem felsigen Untergrund verbundene Gesteinsplatten handeln. Das Bild davon muss heute mit früheren Zeiten nicht mehr voll übereinstimmen, weil die im Laufe der Jahrtausende ständig wirkende Erosion sowie auch die in der Neuzeit eingetretenen Flussregulierungen mit Verminderung von Nebenarmen und daraus folgender Erhöhung des Wasserspiegels mit zu beachten sind. 
Das bisherige Bemühen um eine Antwort aus allein sprachwissenschaftlicher Perspektive hat sich bei der Frage nach dem vollen Motiv für die Benennung als nicht ausreichend erwiesen. Mit den Mitteln der Sprachwissenschaft war der semantische Gehalt des Formativs ian resp. Iani nicht im vollen Umfang ermittelbar. Dazu kommt die unbestimmte zeitliche Dauer der Verwendung dieses Lexems, sehr wahrscheinlich seit germanischer und damit vorchristlicher Zeit bis etwa in die frühe althochdeutsche Zeit. Im Laufe dieser Zeitspanne von weit über tausend Jahren ist auch mit einer bedeutungsmäßigen Veränderung von ian zu rechnen. Aufgrund der Zugehörigkeit von ian zu einer indogermanischen Wurzel mit der Bedeutung ,gehen' war wahrscheinlich zuerst in dem Nomen mit der erschlossenen Semantik ,Gang' a) das ,Begehen' bzw. die ,Begehbarkeit' entscheidendes semantisches Element. Aus der sprachgeschichtlichen Betrachtung der Jena-Namen ließ sich auch zusätzlich erkennen, dass ian ganz speziell b) einen ,Gang durch ein Fließgewässer' bezeichnet haben muss. Es hat sich als weiterführend erwiesen, dass Hans Schmigalla zu dem Schluss führte, dass c) im Fließgewässer auf dessen Sohle naturbedingt so etwas wie ein aufscheinender Gang erkennbar sein musste.

2. „Wäre es nicht treffender, die Bedeutung des Lexems ian- von ,begehbarer/durchfahrbarer Durchgang' auf ,im Flussbett erkennbarer oder markierter Durchgang، einzuengen und die gleichbedeutende Formulierung, im Flussbett erkennbare oder markierte Furt' zuzulassen?" (S. 178 f.). Ein solcher Gang im konkreten Sinn durch ein Gewässer ist nicht überall möglich, sondern an Voraussetzungen gebunden. Diese hat die GGLS recht klar und nachvollziehbar am Beispiel der Jena-Namen vor Augen geführt. Zu den „speziellen Eigenschaften“ eines Ganges durch ein Fließgewässer gehörte ganz gewiss auch die vom Ufer her mögliche Erkennbarkeit des „Ganges“ und seines Verlaufs. Kurz gesagt, es musste in der Realität etwas vorhanden sein, was a) den Eindruck von einem "Gang“ vermittelte und b) auch wirklich begangen bzw. nach Möglichkeit zum Durchgehen/-fahren genutzt werden konnte.

Die sprachhistorische Analyse bietet uns leider nicht die Möglichkeit, alle im Bewusstsein der einstigen Sprachbenutzer mit ian wirklich verbundenen semantischen Inhalte (also alle einzelnen Seme) zu erkennen oder zu erschließen. Das aus sprachlicher Sicht bisher ermittelte Vorkommen von ian bzw. iani in den JenaNamen ließ erstmals die Anwendung des Wortes mit der ursprünglichen Bedeutung ,Gang' auf Gewässerquerungen erkennen. Nach den nun daran anschließend erfolgten Beschreibungen der geologischen Bedingungen für eine solche Flussquerung z. B. konkret an der Saale ist die Semantik von ian in germanischer Zeit nun sogar genauer bestimmbar, etwa mit der Umschreibung, begehbarer/durchfahrbarer Gang auf felsiger oder durch Sedimente ${ }^{7}$ markierter Flusssohle ${ }^{6}$ und damit sicher auch in beachtenswerter Breite. Diese Erweiterung des Bedeutungsumfanges geht nicht aus der Form von ian hervor, sondern lässt sich nur aus der frühgeschichtlichen Anwendung des Wortes auf entsprechend für die Sprachnutzer äußerlich erkennbare (und noch heute vorhandene) Gegebenheiten an der Saale sowie Unstrut erschließen. Damit liegt ein historisch frühes und inzwischen in der

7 Es darf sich dabei jedoch nicht um zeitweilige Ablagerungen handeln. Sediment meint hier Anschwemmungen, die an ein und derselben Stelle immer wieder erneuert werden, etwa beim Eintritt eines Flusses oder größeren Baches in einen größeren Fluss. Folglich handelt es sich bei einer solchen Erscheinung um einen Sonderfall, also um einen erkennbaren Schüttkegel als Folge von Ablagerungen, die ein Nebenfluss kontinuierlich bewirkt. Für diese erläuternden Hinweise danke ich Herrn Prof. Schmigalla. 
deutschen Verkehrssprache verschwundenes Synonym für das uns heute geläufige Wort Furt vor. ${ }^{8}$

Es ist damit zweierlei erreicht worden: sprachgeschichtlich eine erste semantische Abgrenzung zu Furt. Zugleich ist aber auch die Aufgabe gestellt, bei möglichen Fällen von weiterem Vorkommen dieses alten und in der beschriebenen Bedeutung längst archaischen Wortes ian in Eigennamen, stets die Gültigkeit der gewonnenen präzisierten Bedeutungsangabe neu zu prüfen.

3. S. 179 wird in Annahme einer evtl. Bedeutung wie , markierte Furt' gefolgert, „dann wäre Iani/Geni die Benennung eines Ortes an Furten mit einer auffälligen Besonderheit." Diese Schlussfolgerung ist mit den eben gemachten Ausführungen bereits bestätigt worden.

$\mathrm{Zu}$ einer solchen Präzisierung wie ,markierte Furt' wäre die Sprachforschung allein ohne die Ergebnisse aus der Nachbarwissenschaft nie gelangt. Die früh belegten iani-Formen sind uns nur durch Ortsnamen überliefert. Der Bildung dieser Ortsnamen lagen jedoch Wörter aus der Alltagssprache zugrunde. Diese hat freilich in jenen Zeiten niemand aufgezeichnet. Wichtig ist, dass es sich bei ian oder iani p r i $\mathrm{m} \ddot{\mathrm{r}}$ nicht um Ortsnamen-Formen, überhaupt nicht um Onyme gehandelt hat, sondern um ein reines Appellativum, eine Bezeichnung aus germanischer Zeit für eben nur einen ganz speziellen breiten „Gang“ durch ein Fließgewässer. Mehr wissen wir nicht, mehr gibt die sprachliche Form allein nicht her. Wir können allerdings eben das Vorkommen gerade dieses Lexems z. B. auch in mittelhochdeutsch $j \bar{a} n$,Gang' noch nachweisen. Jedoch für die ältere Zeit ist das Lexem - bisher - nur in Namen nahe bei den Flüssen Saale und Unstrut auszumachen. Daher ist im Blick zu behalten, dass es sich um ein vor 2000 oder auch mehr Jahren übliches germanisches Wort handeln kann, mit dem a u ch ein ,Gang durch ein fließendes Gewässer bezeichnet werden konnte. Es ist ja von vornherein nicht auszuschließen, dass das Wort ian darüber hinaus seit germanischer Zeit auch noch bei anderen geografischen Bedingungen verwendet wurde - etwa für einen „Gang“ über ein Gebirge o. ä. ${ }^{9}$ Zum Ortsnamen ist das Lexem ian bzw. in der Form iani erst geworden, als an solchen Übergangsstellen durch Flüsse wie die Saale und Unstrut später Orte bzw. Ansiedlungen entstanden. Die Bewohner in der Umgebung begannen, diese Orte nach ihrer Lage zu benennen und damit von anderen Ansiedlungen zu unterscheiden. ${ }^{10}$

4. „Die ungewöhnliche Benennung mit Iani, und nicht wie andernorts mit einem furt-Namen, wirft die Frage auf, ob nicht ein weiteres Motiv für die Namensgebung bestimmend gewesen sein könnte“ (S. 187).

8 Die GGLS beinhaltet also wesentlich mehr als "Annotationen zu den Jena-Namen“ und hat sich für die Sprachgeschichte als sehr förderlich erwiesen. Für die weit zurückliegende vorschriftsprachliche Zeit konnte aus den Ausführungen der bedeutungsmäßige Gehalt von ian/Iani erweitert und damit präzisiert werden. Die vorgeschlagene Bedeutungsangabe für ian als, im Flussbett erkennbare oder markierte Furt' $^{\star}(\mathrm{S} .178$ f.) erhält daher hier ausdrückliche Zustimmung.

9 Das ist schon daraus zu entnehmen, dass mittelhochdeutsch jān, Gang' bis hin zur Verwendung im Neuhochdeutschen für den ,Gang zwischen den Weinstöcken ‘ - meist ja in Hanglage an Bergen - dafür spricht. Doch auch in diesem Anwendungsbereich besitzt das Lexem eine Bedeutungsspezialisierung über, Gang' hinaus.

$10 \mathrm{Da}$ es in der damals überschaubaren näheren Erlebniswelt keine weiteren solchen Übergänge gab, musste nicht zusätzlich differenziert werden (Zusätze wie Wenigen-, Groß- und Klein- bei den Jena-Namen sind erst im späten Mittelalter hinzugetreten). 
Diese Fragestellung erwächst sicherlich aus der umfassenden logistischen Kenntnis des Verfassers zu einer Vielzahl von Furten. Es ist eine völlig berechtigte und neue Überlegungen auslösende Frage. Auch die Verwendung von -furt zur OrtsnamenBildung ist schon früh erwiesen, bereits seit dem 2. Jahrhundert n. Chr. sind entsprechende Namen überliefert. ${ }^{11}$ Die Verwendung von Furt ist aber sicher deutlich älter als die auf uns überkommenen ersten Aufzeichnungen des Wortes. Es besteht daher Grund zu der Annahme, dass ian- und furt-Verwendung nicht einfach synonym erfolgte, sondern mit einer semantischen Unterscheidung verbunden war. Nach dem geologischen Befund gilt für den Sprachforscher nunmehr jenes differenzierende Kriterium für die Verwendung von ian, das aus den die geologischen Verhältnisse betreffenden Analysen an Saale und Unstrut ermittelt wurde.

Es muss etwas Besonderes vorhanden gewesen sein, das nicht an jeder beliebigen Furtstelle zur Anwendung von ian führte, und das können nach den als markant ermittelten geologischen Bedingungen nur die im Flussbett ausdrücklich erkennbar gewesenen Voraussetzungen für iani gewesen sein. Das aber ist erst aus der GGLS als neue Einsicht und Erkenntnis möglich geworden.

5. S. 187 folgt die nächste Frage: „Könnte nicht das in dem Ortsnamen Iani enthaltene althochdeutsche altsächsisch ian- auch die weitere Bedeutung, Zugang zu Gebieten und Ländern' besessen haben?" Diese Frage lässt sich prinzipiell bejahen. Das Sem ,Zugang' ist generell dem Lexem ian ganz gewiss implizit eigen gewesen, da ja ein Gang mindestens einen Zugang haben muss, an Flüssen jeweils von beiden Seiten. Insofern gehört zur Semantik von Gang auch das Bedeutungselement (Sem), Zugang'. Und ein Gang durch ein Gewässer eröffnet gleichsam eben den Zugang in ein anderes Terrain, Gebiet, eine Region usw. Das aber, meine ich, trifft auch für Furt zu und lässt sich daher nicht als differenzierendes Sem, wohl aber als vorhandenes Sem bezeichnen.

6. Damit ist auch die folgende Feststellung in der GGLS zu unterschreiben: „Wie auch immer die Philologen diese Frage beantworten werden, rein faktisch besaßen die Jena-Orte neben der Durchgangs- auch die Zugangsfunktion." (S. 187). Inwieweit das „Motiv [...] auch [...] des strategischen ,Zugangs' [zu benachbarten Gebieten] nicht auszuschließen" (S. 190) ist, soll hier offen bleiben. Der Sprachgebrauch lässt es durchaus als möglich erscheinen, wenn man innerhalb der Sprechergemeinschaft die bestehende soziale Differenzierung und sich daraus ergebende besondere Absichten und Bestrebungen berücksichtigt.

7. In der „Schlussbemerkung“ (S. 192) wird nochmals zu ian präzise die Frage gestellt, „ob jeder ,begehbare/befahrbare Durchgang“ darunter verstanden, oder anders ausgedrückt, jede Furt damit bezeichnet werden kann.“ Aus der eben gegebenen Abfolge von Antworten ist zusammenfassend und im ausdrücklichen Anschluss an die Untersuchungsergebnisse in der GGLS eigentlich nur noch zu wiederholen und bekräftigend $\mathrm{zu}$ antworten: Die vorgetragenen Ausführungen haben klar zu dem Ergebnis geführt, dass ian/iani nun nicht mebr bedeutungsgleich mit Furt und jedem ,begehbaren/befahrbaren Durchgang' verstanden werden kann. In dieser Erkenntnis von der möglich gewordenen Präzisierung des Unterschieds von ian gegenüber Furt besteht doch der besondere Gewinn und bleibende Wert sowohl für die Sprachgeschichte als auch für die Kulturgeschichte im Untersuchungsgebiet. ${ }^{12}$

11 Friedhelm Debus, Furt, in: Manfred Niemeyer (Hg.), Deutsches Ortsnamenbuch, Berlin/Boston 2012, S. 193.

$12 \mathrm{Zu}$ beachten bleibt, dass sich für ian/Iani bisher eine begrenzte Verbreitung in germanischer Zeit auf den Saale-Unstrut-Raum ergeben hat. 
3. Welcher Fortschritt ist seit der ersten Publikation im Jahr 2015 erreicht worden? Welche Ergebnisse sind inzwischen neu zu verzeichnen?

Es darf wohl auf einige allgemein sichtbar und nachvollziehbar gewordene sowie außerdem zusätzlich deutlich weiterführende Ergebnisse explizit hingewiesen werden: - Die Iani-Namen beruhen auf ursprünglich appellativischen Bezeichnungen. Sie fanden mit Bezug auf Gewässer Anwendung. Allerdings, wie wir nun durch die GGLS von 2016 erkennen konnten und wissen, nur unter bestimmten Voraussetzungen, die in der Realität - sprich im Fließgewässer bzw. infolge des Fließgewässers - eben vorhanden sein mussten. Diese Bezeichnungen wurden schließlich „fest“ und im Sprachgebrauch damit zu Namen, d. h. sie dienten der Identifizierung von bestimmten Referenzobjekten: Stellen in Flüssen mit erkennbar breiter Gangfläche durch das Gewässer. Und das bereits in germanischer Zeit, also im Verlaufe von vielen Jahrhunderten (vielleicht schon lange vor ca. 500 n. Chr.), sicher aber noch vor der Herausbildung des Altsächsischen und Althochdeutschen.

- Als absolut klarer Fortschritt ist zu nennen: Erst die Untersuchung der geografisch-geologischen Gegebenheiten hat die Möglichkeit eröffnet, zu einer genaueren Kennzeichnung der Semantik von ian/iani über nur a), Gang' und b) ,quer durch Fließgewässer ' hinaus zu gelangen. Es ist erwiesen, dass nicht jede begehbare Stelle durch ein Gewässer mit diesem Lexem gekennzeichnet wurde. Es mussten ganz bestimmte außersprachliche Bedingungen gegeben sein. Und diese erst ließen es zu, das Lexem ian/iani zur Bezeichnung zu nutzen. Die Semantik lässt sich heute nun genauer fassen mit der durch die GGLS ermittelten und präzisierenden Angabe c) ,im Flussbett erkennbare Furt' (S. 179) mit offenbar deutlicher Breite.

- Die solche alte Iani-Namen fortführenden Jena-Namen beruhen ihrerseits auf Transonymisierung, also auf Namenübertragung von ursprünglichen FlussstellenNamen an Saale und Unstrut auf die in ihrer Nähe entstandenen Siedlungen in noch voralthochdeutscher bzw. voraltsächsischer Zeit, also nach dem archäologischen Forschungsstand zur Stadt Jena etwa ab dem 7. Jahrhundert.

- Neu ist die gewonnene Einsicht, dass nicht jede Furt mit ian bezeichnet werden konnte. Damit wird zugleich angeregt, künftig die natürlichen Gegebenheiten bei der Untersuchung von Furt-Namen möglichst mit einzubeziehen, um konfrontativ zu den Iani-Namen zu einer vielleicht genaueren Bestimmung des Bedeutungsinhalts zu gelangen.

- Neu ist auch die präzisierte Umschreibung der Bedeutung von ian/iani in der knapp gefassten Form als ,im Flussbett erkennbarer oder markierter Durchgang bzw. vielleicht auch etwas modifiziert aus Sicht des Philologen als ,im Flussbett erkennbare [und von Menschenhand markierte ${ }^{13}$ ] Schwelle/Bank zur Nutzung als querender Gang' o. ä.

- Zwischenzeitlich konnte durch den germanistischen Sprachforscher Peter Wiesinger $\mathrm{zu}$ mittelhochdeutsch $j \bar{a} n$ ein ausgedehntes Wortfeld und seine spezifizierte Verwendung in den deutschen Dialekten vom oberdeutschen Sprachraum in der Schweiz über Bayern bis ins Niederdeutsche, vom Westfälischen über das Thüringische bis ins Schlesische nachgewiesen werden. ${ }^{14}$ Das bietet Anstöße, nach viel-

13 Die erweiterte Angabe „von Menschenhand markiert“ gilt freilich erst für eine relativ späte Zeit, in der eine bildliche Anzeige möglich bzw. zum Teil üblich wurde.

14 Karlheinz Hengst/Peter Wiesinger, Die Jena-Namen in Thüringen in sprachgeschichtlicher, dialektologischer und historischer Sicht, in: Beiträge zur Namenforschung. Neue Folge 51 (2016), S. 3-38, bes. S. 9 f. 
leicht noch verborgenen „Petrifizierungen“ von ian in Onymen Ausschau zu halten.

- Auch seitens der Indogermanistik ist nun bestätigt worden, dass es sich bei den Jena-Namen um einen hocharchäischen Bildungstyp handelt. ${ }^{15}$ Die frühere Annahme eines Flussabschnittsnamens für die Saale hat durch eine zusätzliche Diskussion auch einen Abschluss erfahren. ${ }^{16}$

Die genau formulierten Fragen in der GGLS haben es möglich gemacht, in den Antworten - im Vergleich zu den 2015 getroffenen Aussagen - weit präzisiere Angaben vorzutragen. Möglich geworden sind sie aber erst auf der Grundlage der klaren Erkundungen und Darlegungen zu den geografisch-geologischen Fakten an den Stellen des Vorkommens der Namen mit altem ian/iani. Dem historisch arbeitenden Sprachforscher boten die aufgeworfenen Fragen Gelegenheit, nun seinerseits seine neu gewonnene Einsicht in die alten sprachlichen Verhältnisse darzustellen und auf kulturgeschichtlich aufschlussreiche Seme in germanischer Zeit einzugehen.

Besonders zu erwähnen ist an dieser Stelle eine germanistische Wortmeldung von Norbert Nail aus Marburg im Internet. Er hat u. a. auf weitere Nachweise des alten Wortes jan aufmerksam gemacht. Das ist einmal thüringisch janeweg in der Fuhrmannssprache für , geradeaus ${ }^{617}$ und zum anderen eine beachtenswerte Textstelle aus einer langobardischen Urkunde von 744: ecclesia [...], quae posita est in jano nostro, et de ipso jano circa ipsam ecclesiam largiti sumus terram modiorum 500 [...]. Darüber hinaus vertritt er allerdings im Abgleich mit -stedi in Ortsnamen die Meinung, altes iani sei ein erstarrter Lokativ Singular für ein toponymisch verwendetes Lexem, wobei aber leider Genus und Deklinationsklasse von ian/iani unberücksichtigt bleiben und auch der geologische Befund von Hans Schmigalla eigentlich übergangen wird. Die angeführte Urkundenstelle von 744 lässt Norbert Nail aber semantisch den Bezug auf eine „Ertrags- oder Wirtschaftsfläche“ ins Gespräch bringen. Damit wird die Problematik von Bedeutungserweiterung bzw. Bedeutungsspezialisierung mit neuen Beobachtungen bedacht. ${ }^{18}$

Der urkundliche Beleg von 744 mit der Aussage et de eo ipso jano circa ipsam ecclesiam largiti sumus terram modiorum 500 erfordert, eine auf jeden Fall im 8. Jahrhundert vorhandene Gebrauchsform von jan resp. jani mit einer Bedeutung von etwa ,Fläche, Grund und Boden' zu beachten. Die oben in Verbindung mit ian/iani bei den Flussquerungen und ihrer Erkennbarkeit angeführten Erläuterungen wie „Bank/ Bänke“ oder „Breite“ beinhalten eigentlich auch bereits das Sem Fläche. Darauf wird weiter unten nochmals näher einzugehen sein.

Die insgesamt bisher möglich gewordenen Einblicke in das sprachliche Geschehen und in Benennungsvorgänge im Verlaufe von rund 2000 Jahren werfen auch neue Schlaglichter auf das Alter und den Verlauf von frühen West-Ost-Verbindungswegen. Es ist zu hoffen, dass der eingeschlagene Weg einer transdisziplinären Forschung und interdisziplinären Kooperation eine Fortsetzung finden kann.

15 Harald Bichlmeier, Einige indogermanistische Ergänzungen zur Etymologie des Ortsnamens ,Jena', in: Beiträge zur Namenforschung. Neue Folge 52 (2017), S. 52-63.

16 Vgl. Diskussion: Jena, in: Beiträge zur Namenforschung. Neue Folge 52 (2017), S. 43-66 mit den folgenden Beiträgen: Werner Guth, Der Ortsname ,Jena', S. 43-51; Bichlmeier (wie Anm. 15) und Karlheinz Hengst/Peter Wiesinger, Abschließende Bemerkungen zu den Jena-Namen in Thüringen, S. 64-66.

17 Norbert Nail, Däumlings Deutsch („zum Grimm-Jahr 2012“), online: www.staff. uni-marburg.de/ nail/pdf/daeumlings-deutsch.pdf [Zugriff 15. August 2018].

18 Ders., Philologische Nachlese zum Ortsnamen Jena, online: www.staff.uni-marburg. de/ nail/jenajuni26.pdf [Zugriff 15. August 2018]. 
II. Gibt es eine Verbindung der Jena-Namen mit den Jahna-Namen und dem Wüstungsnamen Rudigene sowie dem Namen Rote Jahna an der Mulde? Antworten auf Fragen zu den Jahna-Namen und ibrer Überlieferung an Elbe und Mulde

Im zweiten Teil seiner Annotationen zu den Jena-Namen hat Hans Schmigalla19 auf einige in Überlieferung oder heutiger Lautung den Jena-Namen an Saale und Unstrut irgendwie nahe kommenden geografischen Namen Bezug genommen. Ausgehend von einer gewissen äußerlichen Âhnlichkeit sowohl zu dem Namen Jena (sowie seinen Überlieferungsformen mit Gene) als auch zu altsächsisch, althochdeutsch jāni und mittelhochdeutsch $j \bar{a} n$ hat er folgende Namen genannt: das Hydronym Jahna, alt Gana, sowie einen Wüstungsnamen Rudigene und eine spätere Form Rothejane.

Gefragt wurde, ob diese Namen als zu den Jena-Namen gehörig anzusehen sind (S. 190) und ob der Gewässername Jahna/Gana eine ähnliche Bedeutung wie die JenaOrtsnamen besitzt. Im Folgenden soll nun zu diesen Fragen eine Antwort gegeben werden. Dazu sind die einzelnen Onyme getrennt voneinander zu beleuchten. An den Anfang gestellt wird das Onym, zu dem es die ältesten historischen Nachweise gibt: die Jabna.

\section{Der Gewässername Jahna}

Das Hydronym Jahna hat seit einem Jahrtausend in der Geschichtsschreibung Beachtung gefunden. Sprachgeschichtlich ist der Name ein besonderes Phänomen. Eingetreten in die Überlieferung ist er durch die Eroberung der Burg Gana, der zentralen Befestigung der Slawen in der fruchtbaren Altlandschaft Daleminze, durch Heinrich I. Diese Landschaft ist als Lommatzscher Pflege heute besser bekannt. Es handelt sich um eine Region, die man aufgrund ihrer guten Böden auch als die Kornkammer Sachsens bezeichnen kann. Der Name mit seiner Konstanz in der geschichtlichen Tradierung als Gana hat kein äußerliches Merkmal eines slawischen Namens. Er zeigt formal keinen Hinweis auf ein slawisches Suffix als Wortbildungselement. Daher ist es und bleibt es unklar, ob das aufgezeichnete Gana in slawischer Zeit überhaupt der Name der slawischen Burg gewesen ist. Angaben dazu freilich werden wir nie mehr erfahren können. Daher bleibt es bei der von den deutschsprachigen Berichterstattern verwendeten Namensform Gana.

\section{Was bietet die historische Überlieferung?}

Es gehört schon zu den ausgesprochenen Raritäten der historischen Überlieferung, dass Widukind von Corvey bereits in der zweiten Hälfte des 10. Jahrhunderts den Namen für eine Burg aus dem heute obersächsischen Sprachraum westlich der Elbe und nordwestlich von Lommatzsch im Raum Riesa ausdrücklich erwähnte. Das geschah freilich nur deshalb, weil Heinrich I. nach Eroberung der Slawenburg Brandenburg mittels Hunger, Schwert und Kälte sofort weiter nach Süden zog und dort die zentrale Slawenburg im Raum Daleminze zwanzig Tage belagerte. Am zwanzigsten Tag nahm er die Burg ein, überließ die Burg als Beute seinen Kriegern, während alle Erwachsenen getötet und Jungen sowie Mädchen in Gefangenschaft genommen wurden. Das bedeutete unausgesprochen wohl die Zerstörung der gesamten Anlage und die völlige Liquidierung bzw. Entführung ihrer Bewohner. Von der Burg dürfte kei- 
nerlei Fortbestand mehr zu erwarten gewesen sein. In der Sachsengeschichte von Widukind liest sich das auszugsweise so: [...] cepit urbem quae dicitur Brennaburg fame ferro figore. [...] et obsidiens urbem, quae dicitur Gana, vicesima tandem die cepit eam. Preda urbis militibus tradita, puberes omnes interfecti, pueri ac puellae captivitati servatae. ${ }^{20}$ Heinrich I. zog anschließend wohl an der Elbe entlang nach Prag: Post haec Pragam adiit cum omni exercitu, Boemiorum urbem [...].21

Die von Widukind vorgenommene Niederschrift (967/968-973) ist zuverlässig. Das gilt auch für die Grafie der Onyme. So wird z. B. auch der böhmische Herzog als Bruder von Bolislav ganz korrekt angeführt als frater [...] erat Bolizlavi.22

Wenige Jahrzehnte später berichtet Bischof Thietmar von Merseburg in seiner in den Jahren 1012 bis 1018 geschriebenen und historische Ereignisse erfassenden umfangreichen Darstellung von einem harten Kampf 1015 um die Burg Meißen, wobei die Truppen von polnischer Seite nahe der Burg Meißen über die Elbe setzten und alles Brennbare bis an den Fluss Jahna niederbrannten: usque ad Ganam fluvium. ${ }^{23}$

Es ist offenbar der Fluss Gana (heute Jahna) bei seiner Länge von rund $30 \mathrm{~km}$ in jener Zeit eine durchaus bekannte Orientierungsgröße gewesen. Er war und ist nördlich von Meißen der längste linke Zufluss zur Elbe. Er wird beidseitig gespeist durch eine ganze Reihe von kleineren Gewässern, zu denen im Quellgebiet bereits drei zufließende Bäche gehören, bevor die Vereinigung mit dem Bach Kleine Jabna erfolgt. Das Gewässernetz der Jahna ist von allen Zuflüssen links zur Elbe das umfangreichste zwischen Dresden und Torgau (Gewässerkarte 1996). Die Jahna war also das zentrale Fließgewässer in Daleminze.

In einer Schenkungsurkunde von Kaiser Heinrich IV. an die Stiftskirche in Meißen 1090 wird wiederum der Fluss Gana erwähnt. Das dabei vergebene Lehen, das bisher ein miles namens Cós im Dienste des Markgrafen Heinrich innehatte, wird lagemäßig so beschrieben: [...] in burcwardo Nimucowa, insuper villam unam Wiscani vocitatum, sitam prope fluvium Gana in regione Thalaminci [...]. ${ }^{24}$ Erwähnt werden der Burgward Mochau ostnordöstlich Döbeln und das ostnordöstlich davon gelegene bzw. benachbarte Dorf Dürrweitzschen (aus altsorbisch *Vysočane, die hoch Wohnenden'25). Fluvius Gana nennt die heutige Jahna, die zur Elbe fließt und bei Riesa mündet.

Diese drei urkundlichen Nennungen mit den gleichlautenden Formen Gana aus dem 10. und 11. Jahrhundert verdienen eine nähere Betrachtung. $\mathrm{Zu}$ beachten ist dabei, dass der heutige Ort Jahna nordwestlich von Lommatzsch am Fluss Jahna liegt. Allerdings ist dort nie eine slawische Burg auszumachen gewesen. Nicht weit enfernt wurden Reste einer Burganlage in der Nähe von Stauchitz entdeckt. ${ }^{26}$ Stauchitz liegt

20 Widukind von Corvey, Res gestae Saxonicae. Die Sachsengeschichte. Lateinisch/ Deutsch, Stuttgart 1992, I, 35.

21 Ebd.

22 Ebd.

23 Thietmar von Merseburg, Chronik, neu übertragen und erläutert von Werner Trillmich, Darmstadt 1957, VII, S. 23.

24 Ernst Gotthelf Gersdorf (Hg.), Urkundenbuch des Hochstifts Meißen, Bd. 1 (Codex Diplomaticus Saxoniae Regiae II/1), Leipzig 1864, Nr. 37, S. 41.

$25 \mathrm{Vgl}$. ERnst Eichler, Slawische Ortsnamen zwischen Saale und Neiße. Ein Kompendium, 4 Bde., Bautzen 1985-2009, hier Bd. 4, S. 63.

26 Vgl. Judith Oexle/Michael Strobel, Auf den Spuren der urbs, quae dicitur Gana, der Hauptburg der Daleminzier. Erste archäologische Untersuchungen in der slawischen Befestigung von Hof/Stauchitz, in: Arbeits- und Forschungsberichte zur sächsischen Bodendenkmalpflege 46 (2004), S. 253-263. 
nordwestlich von Lommatzsch und ganz nahe südlich der Jahna. Die archäologisch ausführlich beschriebene Anlage zwischen Hof im Westen und Stauchitz im Osten mit dem noch bekannten Flurnamen Burgberg dicht südlich der Jahna spricht zumindest für die einstige Lage der urbs Gana. Die bereits prähistorischen Funde lassen auch auf eine Nutzung der Anlage später durch die Germanen schließen, bevor die Slawen den letzten Ausbau vornahmen. Wo auch immer die slawische zentrale Burg sich in der Nähe der Jahna befunden hat, ihre Existenz und Bedeutung ist trotz aller Schwierigkeiten einer genauen Bestimmbarkeit ihrer Lage ${ }^{27}$ nicht zu bezweifeln. ${ }^{28}$

Es war also eine nahe beim damaligen Fluss Gana gelegene Burg, deren Name von Widukind ausdrücklich mit urbs Gana angegeben wird. Es ist aber hier nicht Anliegen, die Ergebnisse der Archäologen zur Lage der Burg zu diskutieren, sondern allein die sprachliche Form ist Gegenstand der Betrachtung. Klar ist, dass der Name des Flusses und der einstigen Burg im Zusammenhang zu sehen sind.

\section{Welche sprachliche Erklärung fand Gana bisher?}

Bisher wurden die historischen Namenformen Gana aufgrund ihrer Lautung und Struktur sowohl in der neueren Orts- als auch Gewässernamenforschung übereinstimmend als vorslawisch, also germanisch aufgefasst. ${ }^{29}$ Und da sich das anlautende $<\mathrm{g}>$ in der Überlieferung als stabil erwies, wurde eine Verbindung mit der indogermanischen Wurzel, wie sie in den Jena-Namen vorliegt und für die germanische Zeit mit $j$-Anlaut rekonstruiert werden konnte, ${ }^{30}$ mit Berechtigung ausgeschlossen. ${ }^{31}$

Bei dem anhaltenden Bemühen um eine überzeugende Etymologie wurde zuletzt erwogen, dass der Gewässername unter Umständen mit einer auf den Fluss übertragenen Geländebezeichnung germanisch *Ganō, die mit altisländisch gan ,das Gähnen“, norwegisch, schwedisch gan ,Schlund, Rachen“ (indogermanisch * $g$ han- gähnen, klaffend öffnen“ oder indogermanisch *ghanó) zusammenhängt. ${ }^{32}$ Bei der Beschreibung der geografischen Gegebenheiten ist es aber zu einer bedauerlichen Verwechselung gekommen, was im Zusammenhang mit der Behandlung von Tausenden von Namen nicht verwunderlich ist. Die angeführte Beschreibung des Gewässerverlaufs mit Käbschütztal und Mündung bei Keilbusch in die Elbe sowie einem Verlauf durch tief eingeschnittene Täler trifft nicht auf die Jahna, sondern auf den verhältnismäßig kurzen Jahnabach im Raum von Meißen zu (zu diesem weiter unten). Aber die historischen

27 Vgl. z. B. dazu die Angaben von H.-J. Vogt in: Joachim Herrmann (Hg.), Corpus archäologischer Quellen zur Frühgeschichte auf dem Gebiet der Deutschen Demokratischen Republik. 7. bis 12. Jh., 4. Lieferung, Textband, Berlin 1985, S. 331.

Der Nachweis einer mehrteiligen und mehrfach ausgebauten, im letzten Stadium geradezu monumentalen Befestigung spricht zusätzlich zu der von Werner Coblenz angeführten Argumentation zu Lage und Größe für diese Lokalisierung der Burg Gana (wie Anm. 26), S. 263.

29 Der in einer Studie zu den Jena-Namen beiläufig erwähnte ältere Erklärungsversuch der Jahna aus dem Slawischen von Johannes Leipoldt aus dem Jahr 1932 ist nicht zutreffend.

30 Hengst/Wiesinger, Jena-Namen (wie Anm. 14).

31 Eichler, Slawische Ortsnamen (wie Anm. 25), Bd. i, S. i 89; Ernst Eichler/Hans Walther (Hg.), Historisches Ortsnamenbuch von Sachsen, 3 Bde., Berlin 2001, hier Bd. 1, S. 449; sowie Albrecht Greule, Deutsches Gewässernamenbuch. Etymologie der Gewässernamen und der zugehörigen Gebiets-, Siedlungs- und Flurnamen, Berlin/ Boston 2014, S. 250.

32 Greule, Deutsches Gewässernamenbuch (wie Anm. 31), S. 250. 
Gana-Belege beziehen sich alle auf die Jahna mit Mündung bei Riesa. Damit entfällt die angeführte außersprachliche Begründung als Motiv für die erwogene Erklärung des Hydronyms. Folglich besteht also ausdrücklich Anlass, nach einer anderen Ausgangsform für den früh überlieferten Namen Gana Ausschau zu halten.

\section{Worauf ist das Hydronym Gana zurückzuführen?}

Da ein geografischer Name in der Zeit seiner Bildung auf ein zugehöriges Objekt referiert, ist auch davon auszugehen, dass die Semantik des Namens die extralinguistische Realität aus der Zeit seiner Prägung reflektiert und bei einer sprachgeschichtlichen Analyse erkennen lässt. Das ist für die weiteren Überlegungen zu beachten.

Die von dem germanistischen Sprachforscher Albrecht Greule im Anschluss an die Leipziger Schule mit Ernst Eichler und Hans Walther sowie dem an der Bearbeitung sowie Endfassung des Lexikons „Historisches Ortsnamenbuch von Sachsen“ ganz besonders beteiligten Germanisten Volkmar Hellfritzsch erwogene germanische $\mathrm{Na}$ mensbildung ist auf jeden Fall zutreffend und muss auch beibehalten werden. Es ist also von einem germanischen Namen mit Übernahme zunächst ins Slawische und später ins Deutsche auszugehen.

Die von Albrecht Greule bereits in Betracht gezogene Wurzel bietet eine Lösung. $\mathrm{Zu}$ urindogermanisch ${ }^{*} \mathrm{~g}_{\mathrm{h}}$ an-, gähnen, klaffend öffnen'33 sind u. a. einzelsprachlich belegt mit Übergang von indogermanisch $/ \mathrm{gh} />\mid \chi / \mathrm{im}$ Griechischen $\alpha \chi \alpha v \eta$ s, weit geöffnet, weit ausgedehnt' sowie griechisch $\chi \alpha$ óvo ,Schlund, Mund', ebenso mit indogermanisch /gh/ > /g/ im Germanischen altnordisch gan ,Schlund' und altnordisch gana ,mit offenem Mund dastehen, gaffen'. Es lässt sich hier unser Hydronym anschließen. Die slawische Vermittlung erfordert den Ansatz einer germanischen Bildung *Gana oder jünger *Ganaha, wobei auffälligerweise der Kurzvokal in der Stammsilbe auch als /a/ ins Slawische übernommen und beibehalten wurde. ${ }^{34}$ Die slawische Form ist uns mit der später altsächsisch überlieferter Form Gana lautgerecht erstmals tausend Jahre später überliefert worden.

Auszugehen ist von einer vor ca. 2000 Jahren (oder sogar noch früher) geprägten Form germanisch *Gana(ba) mit der allerdings nur recht vage bestimmbaren Bedeutung ,Fließgewässer mit auffälligem Merkmal der Mündung (evtl. einem Schlund ähnlich)'. Als Motiv für die Namengebung wirkte möglicherweise eine vermutlich als relativ weit empfundene Öffnung der Jahna im Mündungsgebiet. Und Hydronyme wurden ja bevorzugt am Unterlauf geprägt. Eine diese Erklärung stützende Rolle kann vielleicht auch der geologische Befund bieten. Dazu sei zitiert: „Die Jahna mündet bei Elb-Kilometer 107 von links in den Strom. Aus dem Lößgebiet Lommatzscher Pflege kommend, trägt sie eine ungewöhnlich hohe Fracht an Schwebstoffen und Geschieben in die Elbe ein, was auch nach den letzten Hochwassern an ihrem Schüttkegel zu er-

33 Vgl. Helmut Rix, Lexikon der indogermanischen Verben. Die Wurzeln und ihre Primärstammbildungen, Wiesbaden 2001, S. 193.

34 Für den Hinweis auf eine beobachtbare Gesetzmäßigkeit zur Entwicklung von Kurzvokalen aus vorslawischer Zeit danke ich an dieser Stelle ausdrücklich Herrn Prof. Dr. Albrecht Greule von der Universität Regensburg. Zusammen mit Herrn Dr. Wolfgang Janka hat er in einer Rezension darauf aufmerksam gemacht, dass vorslawische Kurzvokale in Namen bei Vermittlung über das Slawische im Deutschen in der Regel als Langvokale erscheinen, sodass z. B. bei vorslawischen kurzem - $i$ - dann im Deutschen langes $-\bar{l}$ - mit späterer Diphthongierung auftritt; vgl. Namenkundliche Informationen 83/84 (2003), S. 178. 
kennen war [...]. In früherer Zeit dürfte er weit in den Elbstrom hineingereicht und sich als heller ,Gang' von der dunklen Sohle abgesetzt haben." 35 Zugleich wird auch darauf hingewiesen, dass noch heute an dieser Stelle eine Personenfähre verkehrt, was darauf hindeutet, dass es sich um eine sehr alte Furt durch die Elbe an der Mündung des Flusses Jahna handelt. Die aus dem „Schlund“ der Jahna sich ergießende Sedimentablagerung mit einer breiten "Gangführung“ in die Elbe hinein hat vielleicht den Mündungsbereich als verhältnismäßig weit und wahrscheinlich als doch irgendwie beeindruckend erscheinen lassen. Diese Beobachtung zur Mündung kann daher durchaus Motiv für die Bildung des Namens Gana in germanischer Zeit gewesen sein.

Damit wird die von Albrecht Greule im Deutschen Gewässernamenbuch angesetzte Wurzel und ihre Verwendung in germanischer Zeit auch für das Hydronym annehmbar, nun im Sinne von *Gana oder auch *Ganaba als, Gewässer mit auffälligem Merkmal (breitem Schlund/breiter Sedimentschicht) im Mündungsbereich`o. ä.

Fest steht, dass bei der Bildung des Hydronyms Gana keinesfalls eine Ausgangsform mit $j$-Anlaut vorlag. Eine Verbindung mit der geschichtlichen Herkunft und Entwicklung der Jena-Namen zu altsächsisch und althochdeutsch jāni lässt sich $\mathrm{n}$ i c h $\mathrm{t}$ feststellen und auch nicht rekonstruieren, trifft also nicht zu. Für einen alten und wirklich genuinen $g$-Anlaut mit Bewahrung auch im Slawischen spricht zusätzlich das tschechische Hydronym Haná für einen Nebenfluss der March/Morava. Haná, 1183 super Hanam fluvium in Moravia ${ }^{36}$ beruht ebenfalls auf germanisch *Gana mit dem spätereren Übergang von $/ g />/ h /$ im Alttschechischen. ${ }^{37}$ Dieser vergleichbare Name erhärtet nochmals den seit germanischer Zeit bewahrten $g$-Anlaut, der erst im 12. Jahrhundert dem Wandel von $/ g />/ h /$ unterzogen wurde.

\section{Warum scheidet für das Hydronym Jahna ein $j$-Anlaut im Altsächsischen aus?}

Thietmar von Merseburg nennt in seiner Chronik eine ganze Reihe von Namen slawischer oder auch anderssprachiger Herkunft. Betrachtet man die Onyme mit Schreibungen im Anlaut mittels $<\mathrm{i}>$ oder $<\mathrm{j}>$, so finden sich die slawischen Namen Iarimir, Jarizlavus sowie die anderer fremdsprachiger Herkunft Ieremias, Ierusalem, Juda, Iulius Caesar. Thietmar wahrte also den $j$-Anlaut bei Namen aus fremden Sprachen.

Davon gibt es nur zwei Abweichungen. Das ist einmal Geniun mit dem nachträglich getilgten <un> (Jena-Namen) und zum anderen die Burg Gezerisca - Thietmar nennt diese als eine von weiteren acht Burgen ad 981 zur Zeit der Aufhebung des Bistums Merseburg (Thietmar III 16). Die slawische Ausgangsform lautete *Jezerišče (zu *jezer $(o)$,See') und ist zugleich der ursprüngliche Name für heute Tiefensee nordwestlich Eilenburg. ${ }^{38}$ Thietmar erwähnt diese Burg nochmals ad 1015 Geserisca (ThIETMAR VII 24). Es handelt sich dabei um die im altsächsischen Sprachgebrauch im Norden des Erzbistums Magdeburg sowie auch speziell im Bistum Merseburg unter

35 Schmigalla, Felsbänke (wie Anm. 2), S. 195.

36 Ivan LutTerer/Rudolf Šrámek, Zeměpisná jména v Čechách, na Moravě a ve Sleszku, Havličkův Brod 1997, S. 86.

37 Vgl. dazu auch Ernst Eichler/Hans Walther, Die Ortsnamen im Gau Daleminze, Bd. 1, Berlin 1966, S. 120; LutTerer/Šrámek, Zeměpisná jména (wie Anm. 36), S. 85 f., Letztere auch mit Erklärung aus dem Germanischen, aber mit ganz abweichender Semantik in der Etymologie.

38 Eichler, Slawische Ortsnamen (wie Anm. 25), Bd. 1, S. 138. 
den kirchlichen und weltlichen Oberen verwendete Form des slawischen Namens, also die altsächsische Aussprache des entlehnten Namens. ${ }^{39}$

Sicherlich liegt weder bei Widukind noch bei Thietmar bei der Grafie Gana eine sprachliche Unkorrektheit vor. Damit sind aber die Schreibungen mit $<\mathrm{g}>$ bei Thietmar in Geni und Gezerisca noch nicht erklärt. Für die Erklärung von Thietmars $<\mathrm{g}>$ für den $j$-Anlaut ist das Altsächsische entscheidend. Da gilt, dass $<\mathrm{i}>$ und $<\mathrm{g}>$ verwendet wurden, um den Halbvokal / $j$ / auszudrücken. ${ }^{40}$ Dazu heißt es: „Im Anlaut stehen $g$ und $j$ besonders vor $e$ und $i$ "41 wie in Gerusalem. Diese Erscheinung war aber nicht auf das Altsächsische beschränkt. Bekannt ist, dass jener und auch jäten bereits im Althochdeutschen mit $g$-Formen vorkommen und im deutschen Sprachgebiet weite Verbreitung gefunden haben. Althochdeutsche Grammatiken vermerken, dass vor /e/ und /i/ anlautend meist $<\mathrm{g}>$ statt $<j>$ steht. Und für das 8./9. Jahrhundert wird für das Althochdeutsche $<\mathrm{g}>$ als die normale Schreibung für $/ j /$ bezeichnet, neben der auch $<$ i $>$ vorkommt. ${ }^{42}$

Die von der Germanistik nachgewiesenen Schreibungen von $<\mathrm{g}>$ für / j/ vor hellem Vokal sind auch die Ursache dafür, dass auch die rekonstruierte germanische Form zu erschlossenem althochdeutsch, altsächsisch *jān-sowie zu mittelhochdeutsch $j \bar{a} n$ mit der Bedeutung ,Gang, Durch-, Übergang' und die Form jani mit Schreibung < $<$ gene $>43$ in den Jena-Namen an Saale und Unstrut bei Thietmar als Geni erscheint. ${ }^{44}$

Wir haben in der langen Belegkette des Gana-Namens vom 10. Jahrhundert bis zum Ende des 15. Jahrhunderts keine einzige Form mit einem $j$-Anlaut. Das spricht eindeutig und zweifelsfrei dafür, dass bei dem Hydronym Jahna der heutige $j$-Anlaut nicht ursprünglich vorhanden war und von einem ursprünglichen $g$-Anlaut auszugehen ist.

\section{Wie ist die dauerhafte Bewahrung von Gana zu erklären?}

Es ist nun zunächst eigentlich schon erstaunlich, dass bei Widukind von Corvey eine so genaue Kenntnis des Namens einer slawischen Burg - für ihn weitab nahe der Elbe im heutigen Meißnischen gelegen - vorhanden war. Zu erklären ist das wahrscheinlich am besten anhand von zwei Fakten:

Erstens war die slawische urbs Gana sicher im Fränkischen Reich schon lange vor dem Kriegszug von Heinrich I. eine bekannte Größe. Es hat sich bei dieser Burg nicht um eine, sondern offensichtlich um die entscheidende slawische Festung, eine Burg mit

39 Jedenfalls erscheint $\langle\mathrm{g}>$ in diesen Namen nicht für slawisches Phonem /g/, wie das sonst bei Thietmar üblich ist (vgl. Ortsnamen wie Geusa südwestlich von Merseburg und Görschen südöstlich Lützen und ihre Überlieferung mit $<\mathrm{g}>$ auch bei Thietmar). Johan Hendrik Gallée, Altsächsische Grammatik (Sammlung kurzer Grammatiken germanischer Dialekte A/6), mit Berichtigungen und Ergänzungen von Heinrich Tiefenbach, Tübingen ${ }^{3} 1993$, S. 147, $\mathbb{S} 185$. Vgl. auch althochdeutsch genèr neben jenèr ,jener' bei Rudolf Schützeichel, Althochdeutsches Wörterbuch, Tübingen 51995, S. 177.

41 GalléE, Altsächsische Grammatik (wie Anm. 40), S. 151, \ 194.

42 Ingo Reiffenstein/Thomas Klein/Helmut Gneuss, Althochdeutsche Grammatik I: Laut- und Formenlehre (Sammlung kurzer Grammatiken germanischer Dialekte A/5/1), Tübingen ${ }^{15} 2004$, S. 114, \$ 116 , Anm. 1.

43 Es erfolgte also konventionell die Wiedergabe des Umlauts ae mit $<\mathrm{e}\rangle$ sowie des $j$-Anlauts mit $<\mathrm{g}>$.

44 Hengst/Wiesinger, Jena-Namen (wie Anm. 14), S. 10-15. 
Schlüsselstellung zwischen dem Gebiet der slawischen Heveller und dem Herzogtum Böhmen, im Sprachgebiet der Surbi gehandelt. Diese urbs Gana hat als zugleich zentrale Burg in Daleminzien am ehesten nicht allzu fern von einer Altstraße gelegen und einen Übergang über die Elbe zu den dort östlich ansässigen Slawen gesichert. Damit war sie einerseits Händlern, andererseits aber bestimmt auch den Obrigkeiten westlich der Saale schon lange gut bekannt. Das erklärt den frühen Bekanntheitsgrad der Burg sogar weit westlich vom Slawenland. Es verwundert daher nicht, dass Heinrich I. sowohl im Land der Heveller als auch in dem sich südlich anschließenden weiteren Slawen-Land über genaue logistische Kenntnisse verfügte. Er ist ja ganz zielorientiert an die für die Unterwerfung des Gebietes bis zur Elbe strategisch entscheidende Burg Gana gezogen und hat dort so lange ausgeharrt, bis die Festung im Winter fallen musste. Wir können also davon ausgehen, dass der historische Name Gana und die politische Bedeutung der Burg im Fränkischen Reich mindestens seit dem 9. Jahrhundert gut bekannt waren.

Zweitens dürfen wir infolgedessen auch annehmen, dass der Name Gana durch den erfolgreichen Kriegszug von Heinrich I. nochmals zusätzlich weithin bekannt wurde, also damit bestimmt auch im Kloster Corvey ab 929 zum Gesprächsstoff gehörte. Von da an waren aber nun mit dem Namen Gana ganz entscheidend neue und wesentliche Fakten verbunden. Der Umfang der mit dem altsächsischen Laut- und Schriftbild Gana verknüpften gespeicherten Informationen hatte sich sowohl verändert als auch bedeutend erweitert. Geblieben war die altniederdeutsch übliche Form. Bei Widukind tritt sie erstmals auf in der Grafie Gana als eine altsächsische Form im lateinischen Text, allerdings für ein im östlichen slawischen Sprachgebiet befindliches reales Objekt.

Auffällig ist außerdem, dass auch Bischof Thietmar von Merseburg mit Muttersprache Altsächsisch ebenfalls genau die Schreibform Gana verwendet, nur mit dem Unterschied, dass er sie seinen Lokalkenntnissen entsprechend als Name für den Fluss nennt. Und auch in der Urkunde von Heinrich IV. 1090 wird wieder der Fluss mit Gana benannt. Die bei den Niederschriften 1012 bis 1018 und 1090 vorhandene Ortskenntnis berechtigt zu dem Schluss, dass mit Gana ein ursprünglicher Gewässername vorliegt. Die Lage der slawischen Burg nahe der Gana hat dazu geführt, dass auch die Burg von den altsächsisch sprechenden Obrigkeiten so benannt wurde und unter dem Exonym Gana im Fränkischen Reich bekannt war.

Das Hydronym germanisch *Gana(ba) konnte von den Slawen ohne Schwierigkeit als *Gana übernommen und fortgeführt werden. Der Name wurde dabei vielleicht sogar an ein altes slawisches Lexem angeschlossen, das gut belegt ist mit bereits urslawisch *gana ,Neid, Zank, Streit' als Bildung zu urslawisch *ganati ,sprechen' und verwandtem "ganiti streiten' usw. ${ }^{45}$ Folglich ist es nicht direkt auszuschließen, dass das Hydronym vielleicht in slawischer Zeit auch als Name für die Befestigungsanlage genutzt wurde, dann aber im Unterschied zum Gewässernamen vermutlich doch mit einem toponymischen Suffix.

7. Was ist außersprachlich noch beachtenswert?

Der frühhistorische Befund zum Gebiet um Riesa sowie an der Jahna spricht nicht gegen, sondern eher für die bereits ausgeführten Darlegungen zur sprachlichen Entwicklung der Form Gana. Zur Ur- und Frühgeschichte von Sachsen heißt es in einem

45 Vgl. Oleg Trubačev, Ėtimologičeskij slovar`slavjanskich jazykov, Bd. 6, Moskva 1979, S. $99 \mathrm{f}$. 
erläuternden Band zum „Atlas zur Geschichte und Landeskunde von Sachsen“ ausdrücklich:

„Das Verbreitungsgebiet der archäologischen Fundstellen aus der frühen vorrömischen Eisenzeit zeigt drei Schwerpunkte: das Bautzener Umland bis zur Neiße, das Elbtal mit Ausweitungen auf die Nebenflüsse im Raum Riesa [Hervorhebung K. H.] sowie das Leipziger Land. [...] Das archäologische Besiedlungsbild zeigt insbesondere im östlichen und mittleren Sachsen eine deutliche Affinität zu Fließgewässern. An Neiße, Schöps, Spree und Schwarzer Elster ebenso wie an Elbe, Jabna oder Döllnitz reiben sich die Fundstellen wie Perlen an einer Schnur [Hervorhebung K. H.]. Ganz offensichtlich bestand in der Nähe zu fließendem Wasser ein wesentliches Besiedlungsmerkmal.“46

Das Flüsschen Döllnitz ist elbeabwärts der nächste linke Zufluss zur Elbe nach der Jahna und mündet nordwestlich von Riesa. Das Hydronym ist eine slawische Bildung und geht zurück auf altsorbisch *Dol'nica zum Adjektiv *dol'ny , unten gelegen", was also genau den geografischen Gegebenheiten entspricht.

$\mathrm{Zu}$ diesen Angaben sind eigentlich die Beobachtungen von Hans Schmigalla zu den beiden links zur Elbe fließenden Jahna-Gewässern als passend und bestätigend zu beurteilen.

8. Was ist zur weiteren Geschichte des Namens Jahna zu beachten?

Die Fortsetzung in der Überlieferung des Hydronyms Jahna bietet der Ortssname Jahna. Eine ausführliche Darstellung dazu liefert der erste Band der zweiteiligen Monografie „Die Ortsnamen im Gau Daleminze“.47 Ohne die dort angegebenen Quellennachweise zu wiederholen, folgen hier die einzelnen Formen nochmals, um vor allem die Stabilität im Anlaut zu verdeutlichen. Es sind nach dem Gewässernamen 1095 fluvius Gan ${ }^{48}$ und 1150 bur[g]wardus ad Ganam ${ }^{49}$ für den Ort: 1203 ecclesia in Gan, 1299 Gana, 1317 Gana in villa ad sanctum Gothdehardum vulgariter nominata, 1470 Gahna, 1500 Jhan, 1552 Gane, 1555 zur Jane. Die Herren zu Jahna sind seit Anfang des 13. Jahrhunderts nachgewiesen mit folgenden Formen: 1206 Robertus de Gane, um 1210 Heinricus et Gero de Gan, 1255-1266 Heiddenricus de Gana, Gane, 1269, 1282 Sifridus, Schibeco de Gana, Gane, 1278, 1295 Heinricus de Gana, Gane, Gain, 1290 Johannes de Gana etc.

Es besteht kein Zweifel, dass der Ortsname den ursprünglichen Gewässernamen bzw. auch den in slawischer Zeit beibehaltenen Lehnnamen *Gana - fortführt.

46 Ronald Heynowski, Die frühe vorrömische Eisenzeit, in: Ders./Robert Reiß, Ur- und Frühgeschichte Sachsens (Atlas zur Geschichte und Landeskunde von Sachsen), Beiheft zur Karte B I 1.1-1.5, Leipzig/Dresden 2010, S. 102.

47 Eichler/Walther, Ortsnamen im Gau Daleminze (wie Anm. 37), S. 120.

$48 \mathrm{Vgl} 1095$ villam Wisinana vocitatam, sitam prope fluvium Gan, in: Отто Posse (Hg.), Urkunden der Markgrafen von Meißen und Landgrafen von Thüringen 948-1099 (Codex Diplomaticus Saxoniae Regiae I/A/1), Leipzig 1882 (im Folgenden: CDS I/A/1), Nr. 170, S. 358 f., mit Erwähnung von Weitzenschenhain, heute zu Lommatzsch gehörig, noch 1435 Wisznen, aber mit Eindeutung von -hain ab 1469 Wiczenhayn usw.; EICHLER/Walther, Historisches Ortsnamenbuch (wie Anm. 31), Bd. 2, S. 573.

49 Die Urkunde betrifft das Dorf Salbitz östlich von Oschatz, zur Parochie Jahna gehörig, mit Angabe villam unam [...] ad Ganam sitam; Oтто Posse (Hg.), Urkunden der Markgrafen von Meißen und Landgrafen von Thüringen 1100-1195 (Codex Diplomaticus Saxoniae Regiae I/A/2), Leipzig 1889, Nr. 223, S. 154. 
Gemeint ist der Ort mit ehemaligem Rittergut östlich Mügeln bzw. nordwestlich Lommatzsch südlich vom Fluss Jahna, heute zur Gemeinde Ostrau gehörig.

\section{Woher kommt plötzlich nach 1500 das anlautende $<j>$ im alten Namen Gana?}

Es ist bei der bisherigen Durchleuchtung der historischen Namenformen sicher allgemein ersichtlich geworden, dass in Gana kein ursprüngliches germanisches Wort mit einem Phonem /j/ im Anlaut enthalten sein kann. Die Erklärung für das plötzlich nach 1500 einsetzende $<j>$ in der Überlieferung und die dem auch entsprechende Aussprache mit [j] im Anlaut ist in den denkenden Köpfen der gebildeten Schreiber in den Kanzleien zu suchen. Sie beachteten bei der Fixierung von Toponymen und Hydronymen deren semantischen Inhalt. Wenn nun ein Name nicht recht durchschaubar war, suchten die Notare nach einem Grund dafür. Dabei beachteten sie auch die ihnen geläufige Mundart. Sie wussten, dass in der alltäglichen Kommunikation in der Mundart ein eigentlich „korrektes $j$ “ im Anlaut als [g] gesprochen wurde, also z. B. [gung] für Junge, [gār] für Jahr usw. Das bewog dann dazu, statt wie bis dahin üblich <g>, nun an dieser Stelle $<j>$ zu schreiben. Diese kanzleiseitige Einflussnahme war also eine als „hyperkorrekt“ zu bezeichnende Handlung. Diese erfolgte abweichend von der sprachgeschichtlichen Entwicklung und beinhaltete eine quasi "amtliche" Rücksetzung für den mundartlich seit dem 12. Jahrhundert nachweisbaren - hier aber nicht zutreffenden - Übergang von / $/$ / zu / $g / .50$ Die Schreiber ab dem 16. Jahrhundert wähnten, diesen Wandel von mundartlich $/ j />/ g /$ im Namen zu erkennen und schrieben dann demgemäß den mit / $g$ / gesprochenen Namen mit einem anlautenden $<j>$. Im Wissen um diesen Lautwandel konnte vor allem bei den für deutsche Schreiber undurchsichtig gewordenen Namen mittels Ersatz von / $g$ / durch / $/$ / der eine oder andere Name dem deutschen Sprachsystem angeglichen und scheinbar bedeutungsmäßig verständlich gemacht werden.

Diese anscheinend verbessernden Eingriffe in den Kanzleien setzen bei geografischen Namen weithin ab Ende des 15. Jahrhunderts ein und werden daher in unseren onomastischen Untersuchungen seit Jahrzehnten als scheinbare sekundäre semantische Verankerung (SSSV) oder auch als sekundäre semantische Motivierung (SSM) bezeichnet. Bei dem Namen Jahna ist auch die Wirkung der Analogie zu den deutschen Siedlungsnamen mit dem Erstglied Jahn- wie in Jahnsbach, Jahnsdorf, Jahnshain als Wirkungsfaktor mit zu bedenken.

Da der Gewässername in der voraltsächsischen bzw. voralthochdeutschen Form *Gana auch ganz gewiss von den Slawen übernommen und verwendet worden ist, lässt sich eine zwar in der urkundlichen Tradierung nicht explizit als altsorbisch gekennzeichnete Form *Gana erschließen. Es ist zu vermuten, dass die Slawen diese Form von der Struktur her als Simplex verstanden bzw. empfanden, vergleichbar mit slawischen Gewässerbezeichnungen wie slawisch rěka ,Fluss‘ oder voda, Wasser‘, und somit unverändert, also ohne Suffigierung, nutzten.

Auf die ursprüngliche $g$-Lautung weist auch die bekanntlich sehr konservative und daher Quellenwert besitzende Mundartform hin. Sie lautet zu Fluss und Ort Jahna unverändert gūonə, gōnə. ${ }^{51}$ An der Ursprünglichkeit des g-Anlauts in den Gana-For-

50 Vgl. Rudolf Grosse, Namenforschung und Geschichte im Mittelalter, in: Rudolf Fischer (Hg.), Leipziger Studien. Theodor Frings zum 70. Geburtstag (DeutschSlawische Forschungen zur Namenkunde und Siedlungsgeschichte 5), Halle/Saale 1957, S. 63-79, hier bes. S. $72 \mathrm{f}$.

51 EichleR/Walther, Historisches Ortsnamenbuch (wie Anm. 31), Bd. 1, S. 449. 
men und an dem hohen Alter des Flussnamens Jahna lässt sich also nicht rütteln. Eine Vebindung mit den Jena-Namen bestebt sprachgeschichtlich nicht. Der Gewässername Jahna/Gana besitzt auch keine den Jena-Ortsnamen entsprechende Bedeutung.

10. Welche Beziehung besteht bei den heutigen Jahna-Orten nahe Meißen zum Hydronym Jahna?

Ganz klar vom Gewässernamen Gana/Jahna zu unterscheiden sind zwei weitere Orte, die ebenfalls den Ortsnamen Jahna führen: Es sind die Orte Niederjahna und Oberjahna, die heute zur Gemeinde Käbschütztal gehören und westlich von Meißen zu finden sind. Ihre Ortsnamen haben ursprünglich nichts mit dem Namen Jahna zu tun. Sie sind überliefert 1205/1206 in utroque Kanin, 1285 superior Canin, 1336 Kanyn superior, 1486 Nyder Khayne und schließlich 1547 Oberjahn, und sie beruhen auf einer altsorbischen Ausgangsform *Kanin, Ort eines $\operatorname{Kan}(a)^{`} .52$

Erst nach 1500 sind diese Ortsnamen an den Namen Jahna angeglichen und so mit ihm sekundär verbunden worden. Die Gründe für diese Veränderung der älteren Namensform sind dieselben wie oben beim Hydronym Jahna angeführt. Und die kanzleisprachliche Einflussnahme auf zuerst das Schriftbild und danach auch allmählich auf die Lautgestalt ist wiederum ab dem 16. Jahrhundert zu beobachten.

\section{Wie steht es um den Jahnabach?}

Die beiden zuletzt genannten Orte durchfließt ein Bach. Er trägt heute den Namen Jahnabach ${ }^{53}$ und mündet bei Keilbusch, einer Häuslerzeile in der Flur Gasern, nordnordwestlich von Meißen, in die Elbe. Dieser Jahnabach wird sicher erst in der Zeit nach 1500 seinen Namen nach den ebenfalls in jener Zeit geänderten Siedlungsnamen erhalten haben. In dem hier behandelten sprachlichen Zusammenhang mit dem alten Gewässernamen Gana, heute Jahna, kann das Hydronym Jahnabach daher keine tragende Rolle übernehmen. Diese zuletzt genannten Ortsnamen Nieder-/Oberjahna sind eindeutig slawische Bildungen und erst spät ganz sekundär umgedeutet und an Jahna angeglichen wurden. ${ }^{54}$

Für eine mögliche Kontinuität eines ursprünglichen $j$-Anlauts kann der Name Jabnabach nicht herangezogen werden. Der Bach ist vergleichsweise auffallend kurz und ohne weitere Zuflüsse. Zur Unterscheidung von dem kleinen Fluss Jahna erhielt der Bach den Zusatz - bach.

12. Wie verhält es sich mit den Toponymen Rudigene und Rote Jabne?

In der Fachliteratur finden sich die Formen $†$ Rotbejane und Rot(b)e Jabne 55 für einen heutigen Wohnplatz bzw. Ortsteil Rothe Jabne. Damit verbunden wird eine ganz vereinzelt nur einmal auftretende Überlieferungsform von 1350 Rudigene in einer Auf-

52 Ebd., S. 449 f.

53 Gewässerkarte 1:200000. Freistaat Sachsen, Landesamt für Umwelt und Geologie, Dresden 1996.

54 Vgl. Eichler/Walther, Ortsnamen im Gau Daleminze (wie Anm. 37), S. 121 f.; EichLER/Walther, Historisches Ortsnamenbuch (wie Anm. 31), Bd. 1, S. 449 f.

55 Eichler/Walther, Historisches Ortsnamenbuch (wie Anm. 31), Bd. 2, S. 312. 
zählung von damals bestehenden Orten rechts der Mulde in der Nähe von Eilenburg. Die Textstelle im Lehnbuch Friedrichs des Strengen lautet so: Otto de Tiffinse et eius filius habent a domino castrum Tiffinse [...] item Wetrow, Zcweyndorf, Kuckindorf et Rudigene villas. ${ }^{56}$

Nach dem heutigen Forschungsstand handelt es sich bei Wetrow eindeutig um den Namen der Wüstung Wiederau nördlich Paschwitz und damit ostnordöstlich von Eilenburg, 1289 Wethrowe, eine Bildung zu altsorbisch *větr, Wind', als Siedlungsname altsorbisch *Větrov-, windiger, zugiger Ort ${ }^{‘} .57$

Auch Zweyndorf ist der Name für eine Wüstung „unbestimmter Lage in der Gegend um Eilenburg“. Zugleich handelt es sich um eine ganz einmalige Nennung, sodass eine klare Aussage zu dem Namen erschwert bleibt. ${ }^{58}$ Im Vergleich mit Ortsnamen wie Zweenfurth und Zweibrücken in Sachsen ist auf eine ,Siedlung bei zwei Dörfern' zu schließen.

Kuckindorf als deutsche Prägung tritt auch später noch auf: 1378 Kukendorf, 1459 Kuckendorff und 1529 Kaukendorff und wurde wohl im 15. Jahrhundert wüst. ${ }^{59}$ Die Wüstungsforschung hat auch diesen einstigen Ort ebenso wie Zweyndorf nördlich Paschwitz lokalisiert.

$\mathrm{Zu}$ Rudigene als einstiger villa ist noch später belegt 1529 Radichin ein wust dorf und dorfmark, und ein Restbestand ist in Gestalt eines Vorwerks bei Mensdorf (1314 $M e[n] z$ dorf) mit 1822 Rote Jabne, ein Vorwerk, um 1850 Rothe Jabne, bewahrt. ${ }^{60}$

Es ist zu beachten, dass die nur einmal vorkommende Form Rudigene als Name für ein Dorf in einer Aufzeichnung von 1350 bisher keine überzeugende Erklärung gefunden hat. Insgesamt handelt es sich um eine sprachgeschichtlich durchaus diffizile Form. Die folgende sprachliche Analyse mit dem Versuch einer Interpretation ist daher als ein Diskussionsbeitrag zur Klärung zu verstehen.

In Anbetracht von 1314 villa Rodigen ${ }^{61}$ mit <gen> für das deutsche Diminutivsuffix -chen könnte <gene> in Rudigene eine entsprechende Schreibung mit einem Kasus-e als Lokativform wiedergeben. Es finden sich aber in den daraufhin vergleichsweise abgeprüften Schreibungen für Ortsnamen mit -chen weit und breit keine solchen Auslautschreibungen mit -gene im 14./15. Jahrhundert. ${ }^{62}$ Insofern sind Zweifel

56 Woldemar Lippert/Hans Beschorner (Hg.), Das Lehnbuch Friedrich des Strengen, Markgrafen von Meißen und Landgrafen von Thüringen 1349/50, Leipzig 1903, S. $107 \mathrm{f}$.

57 Eichler/Walther, Historisches Ortsnamenbuch (wie Anm. 31), Bd. 2, S. 588.

58 Vgl. Ernst Eichler, Die Orts- und Flußnamen der Kreise Delitzsch und Eilenburg. Studien zur Namenkunde und Siedlungsgeschichte im Saale-Mulde-Gebiet (Deutschslawische Forschungen zur Namenkunde und Siedlungsgeschichte 4), Halle/Saale 1958, S. $135 \mathrm{f}$.

59 Ebd. S. 53; und Eichler/Walther, Historisches Ortsnamenbuch (wie Anm. 31), Bd. 1, S. 476.

60 Eichler/Walther, Historisches Ortsnamenbuch (wie Anm. 31), Bd. 2, S. $27,312$.

611314 villa Rodigen, villa Welnow, villa Rachewicz im Verzeichnis der Bete von den bona dominorum Ileborch, in: Hans Beschorner (Hg.), Registrum dominorum marchionum Missnensium. Verzeichnis der den Landgrafen in Thüringen und Markgrafen zu Meißen jährlich in den Wettinischen Landen zustehenden Einkünfte 1378, Leipzig/Berlin 1933, S. 363.

62 Vgl. Böhrigen nordöstlich von Hainichen, 1388 Borichen, 1393 Borychen, erst 1544 Bobrigen neben Borichen; Zschöppichen südlich von Mittweida, 1350 in villa Schepichin, 1378 Schepchen, aber 1404 Czepgin - jedoch keine Schreibung - gene. Diese Beispiele stehen für rund 30 in ihrer Überlieferung untersuchte Siedlungsnamen aus dem heutigen sächsisch-thüringischen Raum. 
berechtigt, ob es sich bei Rudigene um einen Ortsnamen mit deutschem Diminutivum handeln kann. Auch die beiden Wüstungsnamen Röthigen im Landkreis Leipziger Land bieten erst viel später Grafien mit <gen>: 1696 Röttgen und 1791 Roethgen, niemals aber mit <gene $>.63$

Möglicherweise handelt es sich bei Rudigene um eine Namengebung für eine kleine, evtl. nur aus einem Anwesen bestehende Örtlichkeit. Als Bildung kommt in Betracht in Analogie zu mittelhochdeutsch rode-ackes ,Rodeaxt', rode-howwe ,Rodehaue` für jeweils eine ,Axt zum Roden' bzw. eine ,Haue zum Roden' eine Form *rode-gene als Kompositum. Allerdings kann es sich bei dieser Bildung aufgrund der Struktur nicht um einen Siedlungsnamen im Sinne von, urbar gemachtes Land an der Furt' gehandelt haben, denn das hätte wie bei anderen -roda-Ortsnamen eine andere Abfolge der onymischen Glieder zur Folge gehabt und *Gene-rode ergeben müssen. Dem Kompositum Rudigene muss daher ein anderes Motiv zugrunde liegen.

Nun ist nahebei eine Furt nachweislich vorhanden gewesen. ${ }^{64}$ Ein Zusammenhang des nur zeitweilig existenten Ortes mit dem Beleg 1350 Rudigene als Zeugnis für $<$ gene $>$ in der Bedeutung, Gänge resp. erkennbar markierte Bank/Fläche/Breite im/ durch ein Fließgewässer ${ }^{\circ}$ ist daher durchaus zu prüfen. Es kann sich dabei um die mundartliche Lautung für die mittelhochdeutsch erwartbare Form *jēne bzw. *jäne mit Ersatz von $/ j /$ durch $/ g$ / in der Mundart handeln. Aber es kann das $<$ g $>$ auch schon auf altsächsischer Aussprache und Schreibung beruhen (vgl. oben Pkt. 5).

Das erste Element Rude- kann 1350 mittelniederdeutsch rüde ,gerodetes Stück Land" wiedergeben oder auch zu mittelhochdeutsch rode in der gleichen Bedeutung gehören. Dazu ist eine Entscheidung schwer zu treffen, da mit der in der Mundart beobachtbaren Hebung von /o/ zu /u/ gerechnet werden muss, vgl. 1494 Rudichin für $\dagger$ Röthigen bei Regis-Breitingen, Landkreis Leipzig.

Der genannte wüste Ort 1529 Radichin ein wust dorf und dorfmark lässt sich sprachlich mit dem älteren Rudigene verbinden. Die Schreibung $<$ Rad $>$ zeigt eine Variante, die sich erklärt aus mittelniederdeutsch rāde neben rōde für ,gerodetes, urbar gemachtes Landstück'. ${ }^{65}$ Und <chin> beruht im 16. Jahrhundert sicherlich auf Angleichung der Schriftform an die Ortsnamen vom Typ Rödgen. Das scheinbare Verkleinerungssuffix in 1529 Radichin ist hier also nicht echt.

Beim Zweitglied von 1350 Rudigene ist aufgrund der nahen Lage zur Mulde zumindest die Annahme einer aus dem Germanischen ererbten Form und ihres Fortbestands im örtlichen deutschen Mundartraum als <gene> aus älter [jäni] nicht auszuschließen. In dem alten slawischen Siedelgebiet muss aber erstens auf jeden Fall auch slawische Vermittlung als möglich erachtet werden. Es kann der Name durch die Slawen wie bei den Jena-Namen durchaus früh aus dem Kontakt mit den germanischen Bewohnern als slawisch *jenb übernommen worden sein. Die Schreibung <gene> in späterer Zeit kann auf mundartlich deutsch $/ g /$ für $/ j / \mathrm{ab}$ dem 12. Jahrhundert beruhen.

63 Von den 30 heutigen Ortsnamen auf -chen, -gen, -ichen, -igen zeigt nicht einer in seiner historischen Tradierung auch nur einmal - gene. Überhaupt sind Schreibungen mit $<\mathrm{g}>$ sehr selten: Höfgen, 1372 Hofegin, 1495 Hoffgen; Förstchen, 1497 Fforschtigen; Dörfchen, 1516 Dorffigen; Rösgen, 1532 Rosgen. Späte hyperkorrekte Schreibungen mit $<$ gen $>$ kommen nur bei drei Ortsnamen im Sächsischen Atlas um Mitte des 18. Jahrhunderts sowie bei drei weiteren Ortsnamen in einem amtlichen Ortsverzeichnis von 1791 vor.

64 Schmigalla, Felsbänke (wie Anm. 2), S. 190 mit Beschreibung der lokalen geografischen Verhältnisse, S. $191 \mathrm{f}$.

65 Karl Schiller/August Lübben, Mittelniederdeutsches Wörterbuch, Bd. 3, Bremen 1881, S. 412, 496. 
Es kann aber zweitens das Lexem auch erst von den deutschen Siedlern im 12. Jahrhundert mitgebracht worden sein und auf altsächsisch / $g$ / für /j/ im Anlaut vor /e/ beruhen. ${ }^{66}$ In Betracht kommt eine alte Mulde-Furt-Bezeichnung. Und diese kann etwa im 12./13. Jahrhundert eine Präzisierung dahingehend erfahren haben, dass sie von anderen Furten durch ein Bestimmungswort näher markiert wurde, nämlich als *rudegene ,Rodungsfurt', also Furt in Nähe eines Rodungsgebietes. Dafür sprechen die nun folgenden Beobachtungen.

Genau da, wo sich die Furt mit dem heutigen Namen „Hainichen Furt“ (1758) befindet, erfolgte zu beiden Seiten der Mulde in der Landesausbauzeit Rodung und Gründung von Neusiedlungen. Das belegen links der Mulde die Ortsnamen Hainichen und Rödigen sowie rechts von der Mulde die Ortsnamen Mensdorf, Gruna und die 1350 noch bestehenden Dörfer mit den Namen Zcweyndorf und Kuckindorf. Es ist daher davon auszugehen, dass die Rodungen ausreichend Motiv waren, die wahrscheinlich erkennbar breite Querung durch die Mulde nicht nur weiterhin mit [gene] zu bezeichnen, sondern den veränderten Verhältnissen entsprechend als *Rudegene. Damit war die Furt eindeutig von anderen Furten unterschieden, die sprachliche Form wurde zum differenzierenden und individualisierenden Namen. Der Name dieser Furt dürfte schließlich auch auf die vermutlich letzte und jüngste Ansiedlung in nächster Nähe zum östlichen Ufer der Mulde mit dem einmaligen urkundlichen Nachweis 1350 Rudigene übertragen worden sein.

Auf weitere, allerdings für unsere Gegend fragliche sprachliche Anknüpfungsmöglichkeiten, wie sie für Ortsnamen in Westfalen erwogen worden sind, die im 13. und 14. Jahrhundert konsequente Schreibungen Ruden- in den heutigen Ortsnamen Rüthen und Altenrüthen im Kreis Soest zeigen, soll hier nicht näher eingegangen werden. Auch eine Eindeutung von mittelhochdeutsch ruote, Gerte, Rute' in die Form Rudigene mit einer bei Hans Schmigalla vermuteten Bedeutung „Rutengang“ scheidet sprachlich - im Unterschied zu dem verglichenen fernen Rothenförde, 960 Rodunfuordi - aus lautlichen sowie strukturellen Gründen ebenso wie ein Personenname in Rudigene aus.

Einen indirekten Hinweis auf mögliches mittelhochdeutsch rode und einen $\mathrm{Zu}$ sammenhang von <gene> mit altsächsisch bzw. althochdeutsch *jāni und mittelhochdeutsch jān liefert die im 19. Jahrhundert bezeugte Form Rothe Jabne. Rothe kann auf Verhochdeutschung von mundartlich [rüdo] beruhen. Und Jabne lässt eine ältere Form ${ }^{*} z u$ dem jāne vermuten. Ein sprachlicher Zusammenhang zwischen Rudigene und Rothe Jabne ist eigentlich kaum zu bezweifeln. An dieser Stelle ist ein regional belegter Nachweis von sowohl der Jabn als auch die Jabne im Thüringischen Wörterbuch zu beachten. Zu beiden Formen erfolgt dort nicht nur übereinstimmend die Bedeutungsangabe ,Reihe geschnittenen Getreides oder gemähten Grases', sondern an erster Stelle steht dies: ,dem einzelnen zur Bewirtschaftung zugeteilter Feld- oder Waldstreifen'. Und als historische Belege werden dazu angeführt: 1650 Gärten und Jähne vom Stadt Graben; die Jähne vor dem Ziegler Teiche. ${ }^{67}$ Die Jähne-Formen sind nach der Alltagssprache aufgezeichnet worden. Jabne hingegen ist als amtliche Form gewählt worden. Dabei muss allerdings bedacht werden, dass auch dies eine alte dialektale Form ist, auf einem alten Plural beruht, aber wie eine Singularform nun gebraucht wurde.

66 Vgl. dazu ausführlich oben unter Punkt 5.

67 Rainer Petzold/Frank Reinhold/Susanne Wiegand, Thüringisches Wörterbuch, Bd. 3, Berlin 2005/2006, S. 298. 
Die modernere Form Rote Jahne kann aber keinesfalls mit einer rötlichen Bodenfärbung und evtl. slawischer Vermittlung erklärt werden. ${ }^{68}$ Es ist auch unwahrscheinlich, dass die erste Konstituente von 1350 Rudigene auf altsächsisch rōd oder mittelniederdeutsch rōt (auch rode) ${ }^{69}$ beruht. Die Autopsie liefert für eine Benennung nach Farbe keinerlei Anhaltspunkte. ${ }^{70}$

Es ist davon auszugehen, dass schon in früher Zeit ein wichtiger und gern genutzter Muldeübergang durchaus besondere Bedeutung für die Verkehrsführung besessen hat. Das heutige deutsche Toponym Rote Jabne kann nach all dem als sprachlich modernisierte Fortführung von älterem Rudigene aufgefasst werden. Und im Unterschied zum Hydronym Jahna/Gana liegt bei Rudigene eine sprachliche Verbindung zu den JenaNamen nahe. Damit ist die von Hans Schmigalla ausgesprochene Vermutung nunmehr nach detaillierter Prüfung der Überlieferung hier doch als zutreffend anzunehmen.

Die Neubenennung ist an der Singularform und Verwendung von Jān im MuldeRaum bei deutschen Sprechern zu erkennen. In der Zeit der Bildung der deutschen Form Rotejabne - vermutlich erst nach 1500 - hat offenbar der Übergang über die Mulde eine Rolle gespielt. Damit ist zugleich das Dialektwort Jān/Jabn indirekt für die Gegend um Eilenburg bzw. das Gebiet an der Mulde im nördlichen Sachsen erwiesen. ${ }^{71}$ Die jüngere feminine Form die Jabne kennzeichnete die Furt durch die Mulde und wurde verkürzt für ,die Jahne (genannte) Querung' nun auch feminin verwendet. Bei der Namengebung in neuerer Zeit ist also Jāne verwendet worden für einen „im Flussbett erkennbaren [...] Durchgang“ “. ${ }^{2}$

13. Ist an der Elbe altsächsisch, althochdeutsch jāni oder mittelhochdeutsch $j \bar{a} n$ je zur Namengebung verwendet worden?

Die schriftliche Überlieferung bietet zwar vieles an einst gebräuchlichem Sprachgut, aber eben nicht zugleich auch alles. Daher ist die Frage von Hans Schmigalla aufgrund seiner Expertise zu den geologischen Gegebenheiten an der Jahna-Mündung in die Elbe, ob der dort noch heute auszumachende Elbeübergang (Fährbetrieb) sowie der beobachtbare Sediment- „Gang“ durch die Elbe möglicherweise in alter Zeit mit jān ,Gang' bezeichnet worden sein könnte, nicht einfach zu beantworten. Die historische Überlieferung lässt dazu nur ein nein zu. Doch ist eben zugleich auch immer die mündliche und kaum offiziell aufgezeichnete Überlieferung zu bedenken. Daher ist es nicht auszuschließen, dass auch an der Elbe ein sich für die Querung anbietender „breiter Gang“ von Sedimenten mit $j a \bar{n}$ in der lokalen Kommunikation bezeichnet wurde. Das kann sogar für den Mündungsbereich des Jahnabaches zugetroffen haben. Denn es ist ja zumindest auffällig, dass gerade diese beiden links zur Elbe fließenden Gewässer - die Jahna und der Jahnabach - deutliche Ablagerungen in der Elbe erkennen lassen. Andererseits ist aber nicht davon auszugehen, dass die Gewässernamen Jahna, alt Gana, und Jabnabach sprachgeschichtlich auf altsächsisch, althochdeutsch

68 Das heißt, dass im Erstelement des Namens auch kein slawisches Etymon ruda, Raseneisenerz' bzw. ,rotbraune Eisenerde' angenommen werden kann und auch kein slawisch-deutscher Mischname vorliegt.

69 Schiller/Lübben, Mittelniederdeutsches Wörterbuch (wie Anm. 65), S. 512.

70 Für die freundliche Auskunft dazu danke ich Herrn Prof. Dr. Hans Schmigalla in Rudolstadt.

71 Das umfassende und sehr gründliche vierbändige Wörterbuch der obersächsischen Mundarten, Berlin 1994-2003, kennt ein entsprechendes Mundartwort nicht.

72 Vgl. Schmigalla, Felsbänke (wie Anm. 2), S. 192. 
$i \bar{a} n$ oder mittelhochdeutsch $j \bar{a} n$ beruhen. Die historische Tradierung und die sprachhistorischen Forschungen zeigen zuverlässig, dass es in altsächsischer und althochdeutscher Zeit keinen Wechsel zwischen den Phonemen /g/ und / $/$ / vor dem Vokal /a/ gegeben hat.

Es lässt sich bestenfalls eine Hypothese formulieren: Im Gebiet des heutigen Obersächsischen kann das weitverbreitet im deutschen Sprachraum dialektal existente jān auch am Oberlauf der Elbe in der Zeit nach der deutschen Besitznahme und Besiedlung bekannt gewesen sein. Es kann zur Bezeichnung einer Flussquerung - bei Vorhandensein der oben beschriebenen Bedingungen - verwendet worden sein. Ein Indiz dafür kann evtl. - muss aber nicht - sein, dass nach 1500 kanzleiseitig beim Bemühen um sprachliche Durchsichtigkeit das Hydronym Gana erstmals mit $j$-Anlaut erscheint, vielleicht begünstigt durch Anschluss an das auch dort damals durchaus mögliche und bekannte Mundartwort jān ,Reihe; Gang'.

Gestützt wird diese Hypothese von der Existenz des Mundartwortes durch einen realen Namen, nämlich durch den Namen Rote Jabne nordöstlich von Eilenburg zwischen Mulde und Doberschütz. Hier bietet der Altwegeverlauf einen Befund zusammen mit der 1758 auf dem Meilenblatt ausgewiesenen „Hainichen Furt“ die Möglichkeit, dass eine entsprechende breite Querung noch mit jän bezeichnet worden sein kann. Allerdings ist nicht mehr auszumachen, ob vielleicht schon ein germanisch *iān-/iani zu slawisch *janb o. ä. führte und dann schließlich als Lehnwort im örtlichen Dialekt als jān oder *jāna fortlebte oder die Namengebung erst mit dem Erbwort aus dem Germanischen von deutscher Seite nach 930 erfolgte. Das feminine Genus von die Rote Jabne kann durch die primär auf die Querung der Mulde sich beziehende Furt (fem. Substantiv) bedingt sein.

Es ist jedenfalls nicht zu übersehen und bestimmt auch nicht zufällig, dass wiederum ein Jahn-Name und noch dazu lagemäßig in Nachfolge zu 1350 Rudigene an einer Furt durch einen Fluss vorkommt. Der Name Rote Furt lebt bis heute fort und ist z. B. auch auf der Karte des ADAC „Unser Sachsen“ eingetragen.

\section{Wie ist das Gesamtergebnis als Resümee formulierbar?}

Zuerst ist sicher zu betonen, dass die Klärung sprachhistorischer Gegebenheiten, Verhältnisse und Zusammenhänge mit Rückblick auf mehr als ein Jahrtausend und dazu nötige Erörterungen bis hin zu Beweisführungen nicht mit wenigen Worten abzutun sind. Bei dem Bemühen, die Ausführungen möglichst verständlich zu bieten, ist es dennoch zugleich nicht immer möglich, die für den Sprachhistoriker zu beachtenden sprachlichen Entwicklungen und lautlichen Veränderungsprozesse bis in alle Einzelheiten auszubreiten. Die jeweils erzielten Antworten zu den eingangs kurz erwähnten Fragen lassen sich als Ergebnisse kurz folgendermaßen umreißen:

- 1350 Rudigene villa in referentieller Kontinuität bis zum heutigen Ortsteilnamen Rote Jabne ist zwar aufgrund der nur vereinzelten Nachweise und der langen Spanne bis zum 19. Jahrhundert nicht ganz sicher erklärbar, lässt aber eine sprachgeschichtliche Verbindung zu altsächsisch, althochdeutsch jāni mit mundartlich beeinflusster Schreibung im zweiten Bestandteil < gene $>$ als zutreffend beurteilen. ${ }^{73}$ Damit ist ein sprachlicher Zusammenhang im weiteren Sinn zu den ebenfalls auf jāni beruhenden Jena-Namen gegeben. Das Zweitglied < gene > im Dorfnamen von

73 Herrn Prof. Dr. Peter Wiesinger von der Universität Wien gebührt an dieser Stelle besonderer Dank für seine Bereitschaft zur Diskussion der gesamten Überlieferungsproblematik sowie für Hinweise zu ihrer sprachgeschichtlichen Bewertung. 
1350 Rudigene villa und moderneres Jabne im Ortsteilnamen lassen sich als Hinweis auf eine in der Nähe befindliche Querung bzw. Furt durch die Mulde nördlich von Eilenburg verstehen.

- Die Neubenennung Rote Jabne macht Jān als Dialektwort für ,breiten Gang, Reihe' auch für Nordwestsachsen wahrscheinlich bzw. setzt sogar das Wort in seiner Verwendung für eine besondere Querung/Furt als bekannt voraus.

- Der Gewässername Jahna für den bei Riesa mündenden kleinen Fluss mit seiner alten Form Gana und ebenso der etwas südlich vom Fluss gelegene Ort Jahna mit konsequenten Gan-Formen bis 1500 beruhen auf germanisch *Gana oder *Ganaha, altsächsisch überliefert als Gana. Der Gewässername ist sekundär auch auf den Ort übertragen worden. Das Hydronym Jahna und auch das Toponym Jahna haben jedoch keine direkten sprachlichen Beziehungen zu den Jena-Namen.

- Die nach der geologisch-geografischen Betrachtung der Jena-Namen einmal wieder ins Blickfeld gerückte Gana-Überlieferung hat zu einem auch sprachwissenschaftlich-namenkundlichen Erkenntnisgewinn geführt. Die bisherigen Untersuchungsergebnisse zum Hydronym und auch zum Toponym Jabna konnten verifiziert und präzisiert werden. Ganz wesentlich hilfreich war dabei, die von Hans Schmigalla beschriebenen außersprachlichen Gegebenheiten einbeziehen zu können und so auch die Motive für die Namengebung in der Frühzeit zu erschließen.

- Der kurze Zufluss links zur Elbe mit Mündung bei Meißen und dem Namen Jahnabach bietet eine sehr wahrscheinlich erst nach 1500 aufgekommene Namensform. Vorher wurden zwei dortige Ortsnamen slawischer Herkunft im 16. Jahrhundert an den Namen Jabna angeglichen. Es bleibt dabei nur als Vermutung bestehen, dass eine vom Mündungsbereich des Baches in die Elbe hineinführende und erkennbare Ablagerung möglicherweise mit dialektalem Jān im Mittelalter bezeichnet wurde und dieses Lexem dann den Ausschlag gab, den kleinen Wasserlauf sowie die beiden Orte (mit zunächst ganz anderen Namen) anzuschließen und mit den Namen (Nieder-/Ober-) Jahna bzw. Jabnabach zu differenzieren. Beide Namen sind dann allmählich auch bei den Bewohnern in der Gegend akzeptiert worden. Insofern kann hier eine gewissermaßen sekundäre Verbindung zu den JenaNamen zwar nicht bewiesen, aber auch nicht völlig ausgeschlossen werden.

Die historisch belegten sprachlichen Formen der Jena- und der Jahna-Namen und ihre Analyse in Verbindung mit den geologisch-geografischen Addenda aus einer Nachbarwissenschaft konnten die Klärung der sprachlichen Wurzeln voranbringen. Der historische Bogen spannt sich dabei über mehr als zwei Jahrtausende. Die Historiker werden die angestrebten Klärungen und Differenzierungen zwischen den Namen ebenso wie die Sprachforscher sicher als Anregung für weitere Untersuchungen zur Präzisierung der einen oder anderen Aussage verstehen. 